\title{
Radar Precipitation Echo and Satellite Cloud Observations of a Maritime Cyclone ${ }^{1}$
}

\author{
Roland E. Nagle and Sidney M. Serebreny \\ Stanford Research Institute, Menlo Park, Calif.
}

(Manuscript received 2 January 1962, in revised form 6 March 1962)

\begin{abstract}
Satellite-observed cloud patterns for five days during the evolution of a major, extratropical maritime cyclone associated with a strong $\Omega$-shaped blocking pattern were studied for the period when the storm existed over a radarscope data collection network. Cloud distributions at 24 -hr intervals were compared with the surface and upper-level synoptic conditions to ascertain cloud-synoptic pattern precipitation pattern relationships. Precipitation distributions are shown in relationship to the cloud features which appear to be characteristic of extratropical maritime cyclones.

In general, the very low percentage of clouds that precipitate at any given time is strongly re-emphasized, as well as the limited area within a storm in which precipitating clouds are found. Shower patterns within cellular type convective clouds are shown to develop in the same configuration as the clouds and to be subject to diurnal effects. These showers were found to have lasted at least two hours, a considerably longer period than comparable continental air-mass showers. Minor cloud vortices were found which persisted along regions of confluence of contrasting air masses around the periphery of the major spiral cloud pattern associated with the storm; these minor vortices appeared to rotate with the gross cloud pattern and were loci of heavy precipitation activity.
\end{abstract}

\section{Introduction}

The degree of organization that meteorological satellite observations from TIROS I² (Sternberg et al., 1960) have shown to exist in the cloud patterns associated with major extratropical cyclones, (e.g., Fritz and Wexler, 1960; Winston, 1960; Bristor and Ruzecki, 1960; Winston and Tourville, 1961) ${ }^{3}$ has raised optimism concerning future advances such observations will bring to the science of weather analysis and prediction (Fritz, 1960). However, the relationships between many meteorological parameters, such as precipitation distribution and intensity, and cloud patterns, are not yet sufficiently known nor understood to consider that the former can be replaced by the satellite cloud observations. Considering the uniformities and repetitive pat-

\footnotetext{
${ }^{1}$ This research was supported by the Air Force Cambridge Research Laboratories of the Office of Aerospace Research under Contract AF 19(604)-5982.

2 The first of a family of weather satellites launched by the National Aeronautics and Space Administration on 1 April 1960.

${ }^{3}$ Widger, W. K., Jr., 1960: Project TIROS (meteorological satellite). Semi-Annual Tech. Sum. Rpt., ARPA Order No. 26-59 Geophys, Res. Dir., AF Res. Div., Bedford, Mass., 26 pp.
}

terns that recent studies ${ }^{4}$ have shown to exist in precipitation associated with maritime extratropical cyclones, knowledge of the relationship between precipitation and satellite-observed clouds in one such disturbance should greatly assist in establishing principles for deducing precipitation patterns in cases where only the satellite cloud observations may be available.

This is a study of a cyclone in the eastern Pacific Ocean during the period 19 May through 23 May 1960 when it existed over a data collection network of airborne and land-based radar stations. The radarscope coverage available during this period is shown in Fig. 1.

The data consist of 35-mm film records of the plan position indicator scope (PPI). Exposures made at the land-based stations were of two successive scans at 15-min intervals, while one exposure every 2 min along the flight track was made at the airborne stations. Viewing these films in cinémotion allows a time-lapse compression on the order of 5000-7000 $x$, which brings out motions and developments that are usually not obvious nor readily observable in the usual radarscope

\footnotetext{
${ }^{4}$ Ligda, M. G. H., R. T. H. Collis and R. H. Blackmer, Jr., 1960: Radar study of maritime precipitation echoes. Final Rpt., Contract NOAS 59-6170-C, Stanford Research Institute, Menlo Park, Calif., 57 pp.
} 


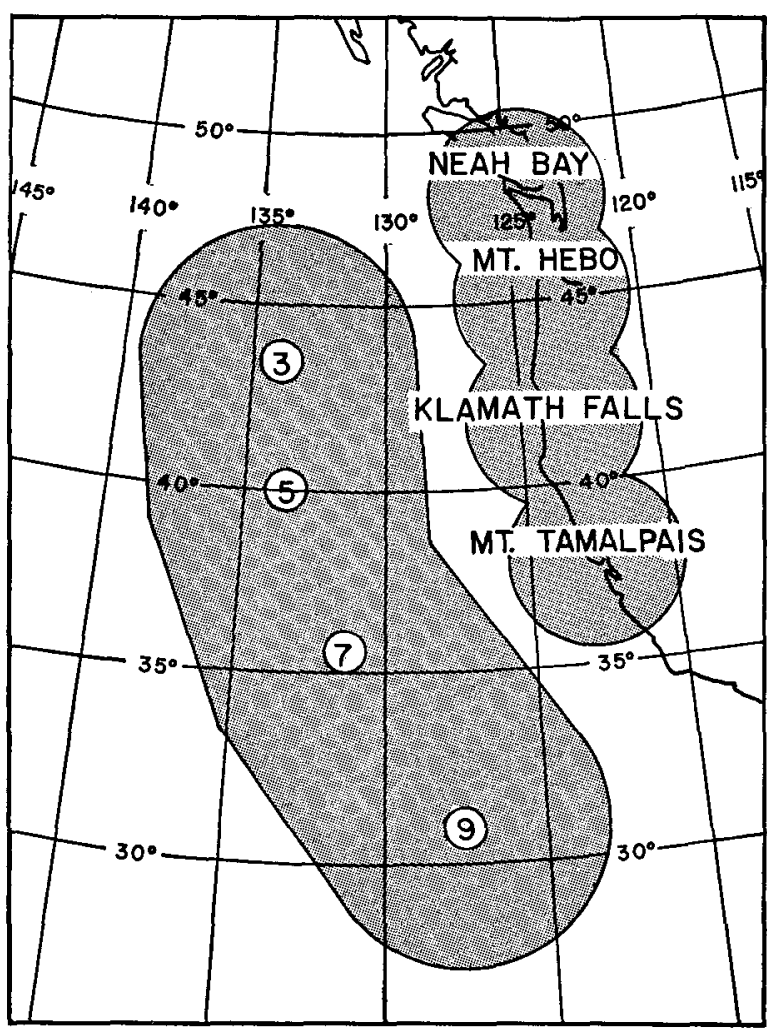

Frg. 1. Radarscope data coverage (circled figures indicate the location of the airborne radar picket stations).

records exposed one frame each sweep. To eliminate ground patterns, aircraft, anomalous propagation, and other nonhydrometeor echoes, and partially because of security considerations, the radar data are presented in this paper in the form of tracings of the weather echoes which existed on the radarscopes at the times of the satellite pictures. These instantaneous composites do not allow depiction of the complicated motions which can be observed when the original films are viewed as a motion picture. Similarly, the tracing technique negates a presentation of the variations in the character (stratiform, cumuloform) and the texture (solid, diffuse, sharpedged, etc.) of the echoes, which are present in the original records and which allow a qualitative estimate of the type and intensity of the precipitation that may be occurring. Because of the limitations in the method of presenting the data, it has been impossible, in this paper, completely to document visually certain portions of the information present in the original radarscope records.

The general configuration of the large-scale pressure pattern over the Pacific Ocean proceeded rather rapidly from one of predominantly zonal orientation on 18 May 1960 to one of extreme meridional orientation by 22 May and then returned to a well-defined zonal flow pattern by 26 May. This extreme and rapid change in the circulation was accompanied by the southward displacement of the cyclones both upstream and downstream from an intense, meridional ridge which had developed in the central Pacific, i.e., a strong " $\Omega$ " blocking pattern (Petterssen, 1956). The sequence of events described and illustrated in this paper began with the so-called "cutting-off" process of the downstream, welldeveloped low pressure cell associated with the above mentioned large-scale pressure pattern and continued through the evolution of the cyclone until zonal flow was once again established aloft. The sequence of surface and $300-\mathrm{mb}$ charts corresponding to this period and illustrating the synoptic developments are shown in Figs. 2a through $2 \mathrm{e}$ and Figs. $2 \mathrm{a}^{\prime}$ through $2 \mathrm{e}^{\prime}$; these charts will be referred to in the description of the storm development. The heavy dashed lines on Figs. 2a' through $2 \mathrm{e}^{\prime}$ indicate tropopause intersections with the 300 -mb level; the heavy arrows are jet stream axes.

Eleven individual wide-angle camera picture sequences from TIROS I were obtained over the Pacific Ocean during the period investigated; these provided an adequate portrayal of the cloud patterns associated with the cyclone at 24 -hr intervals. All of these sequences were obtained within at least $4 \mathrm{hr}$ of the 0000 GMT synoptic observation time; therefore, in the storm description provided in Section 2, the cloud patterns observed on each day of the study may be compared with the synoptic conditions at 0000 GMT. To facilitate the comparisons, the pictures were rectified ${ }^{5}$ and the gross features of the cloud systems observed on each day are shown in schematic form in Figs. 3, 4, 5, 8 and 9. The inherent location uncertainties associated with the TIROS I observations ${ }^{6}$ presented difficulties to the accurate positioning of the cloud patterns. These diffculties were largely overcome by reference to landmarks which were visible somewhere in each sequence of pictures; it is estimated that cloud features shown in figures of this paper are located to within $50 \mathrm{n} \mathrm{mi} \mathrm{of}$ their true locations. Cloud features of particular interest and significance are illustrated in figures of this paper by reproductions of selected photographs obtained from the satellite. Coastlines, when present on these photographs, are outlined, and, on photographs which do not include a view of land masses, a latitude-longitude intersection close to a significant cloud feature has been indicated on the figures. Composite tracings of the precipitation detected by the radar stations at the approximate time of the satellite observations have been superimposed upon the cloud schematic representations to

${ }^{5}$ Glaser, A. H., 1959: A system for the meteorological operational use of satellite television observations. Semi-Annual Tech. Rpt. No. 1, Contract AF 19(604)-5581, Allied Research Associates, Inc., Boston, Mass, 81 pp.

${ }^{6}$ Hubert, L. F, 1961: TIROS I: Camera attitude data, analysis of location errors, and derivation of correction for calibration. MSL Rpt. No. 5, U. S. Weather Bureau, Washington, D. C., $63 \mathrm{pp}$. 


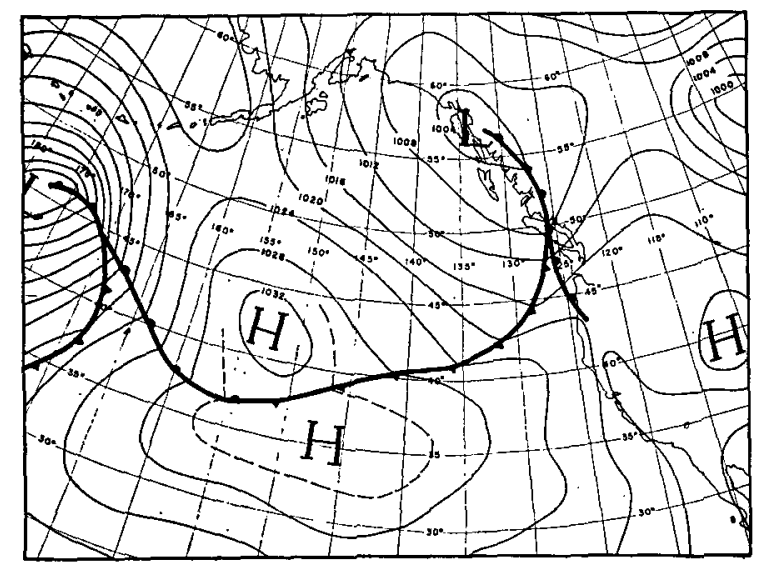

FIG. 2a.

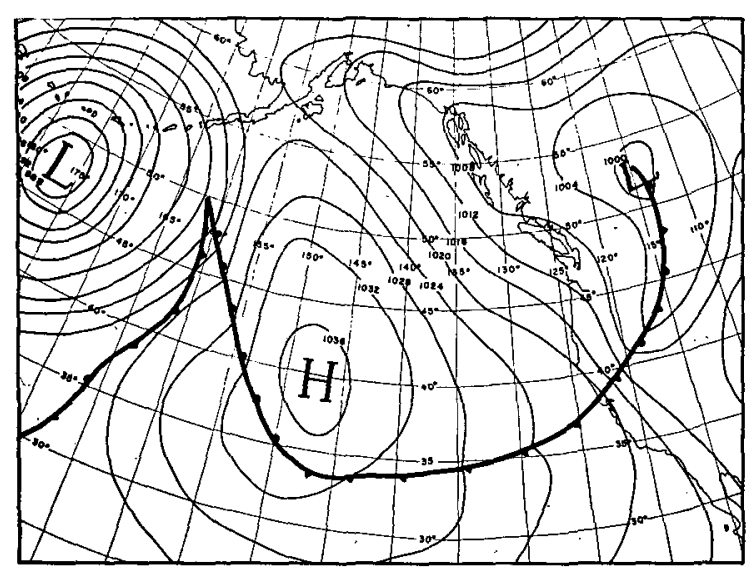

FIG. $2 b$.

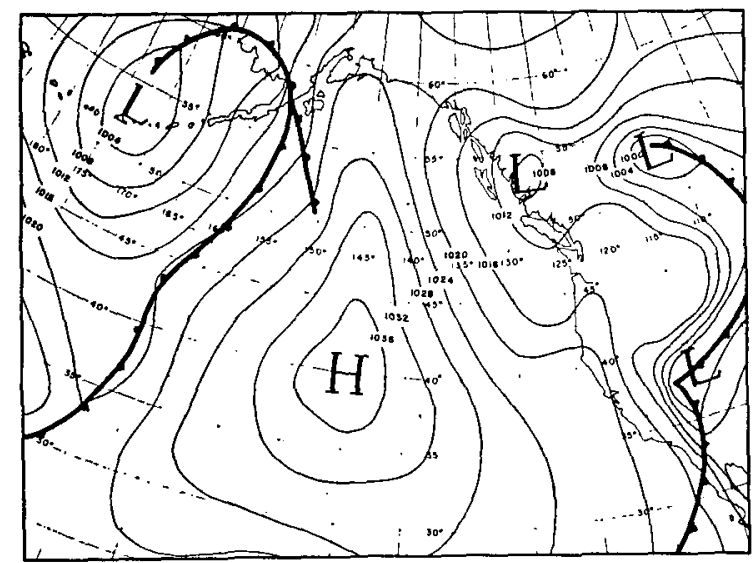

FIG. 2c.

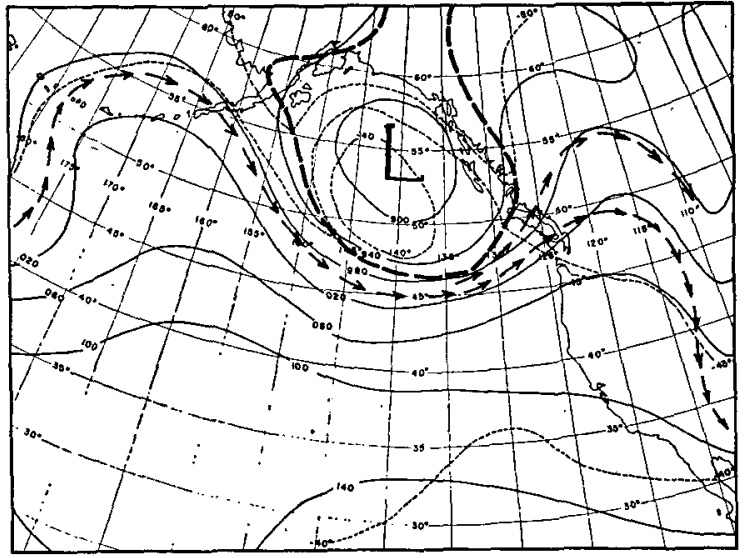

FIG. $2 a^{\prime}$.

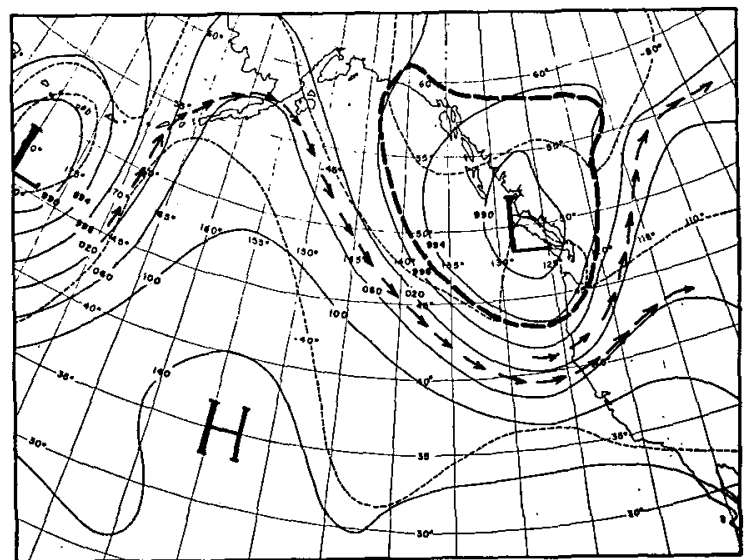

FIG. $2 b^{\prime}$,

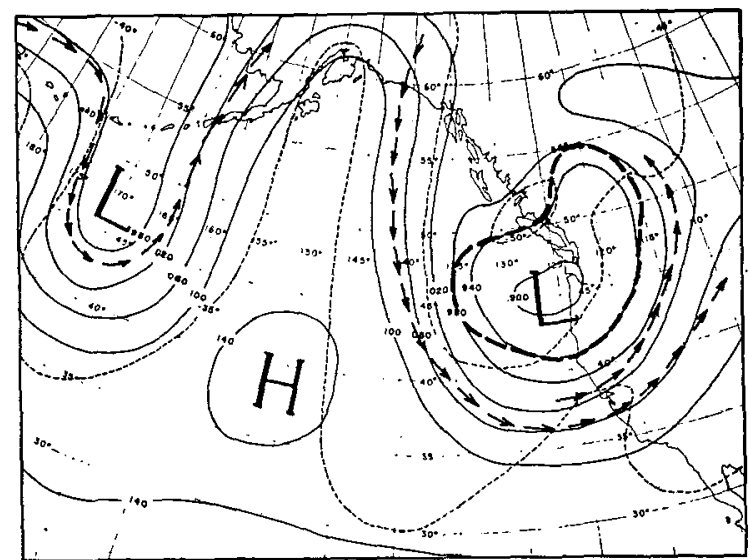

FIG. 2c'.

FIG. 2. Surface and 300 -mb synoptic charts at 24 -hr intervals covering the period from 0000 GMT 20 May through 0000 GMT 24 May 1960 . Contour lines shown by thin solid lines, isotherms by thin dashed lines, jet stream axes by heavy solid arrows, and intersections of the tropopause by heavy dashed lines. (Continued on next page.) 


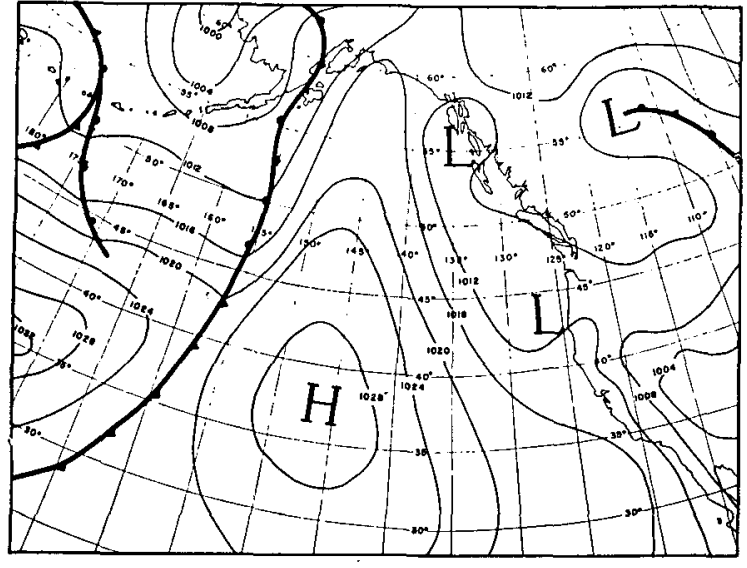

FIG. 2d.

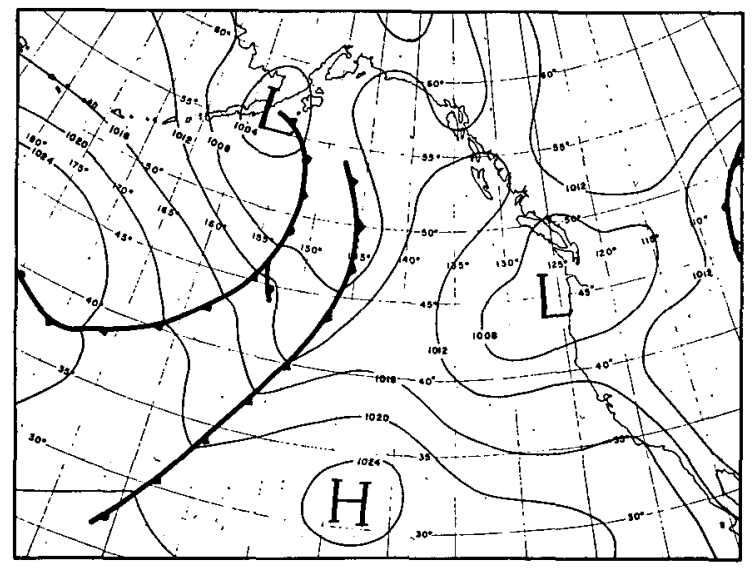

FIG, 2e

illustrate distribution of precipitation which occurred within the storm throughout its development. The relative motions of the precipitation areas are also indicated by the small arrows superimposed on these figures.

\section{The synoptic history of the cyclone}

\section{A. 0000 GMT 20 May 1960}

The 0000 GMT 20 May 1960 surface chart, Fig. 2a, shows an occluded frontal system extending from a low pressure area centered near $56 \mathrm{~N}, 133 \mathrm{~W}$, which was advancing toward the North American continent. This front marked the leading edge of an intense, Arctic airmass outbreak which had been moving across the North Pacific and by this time had dominated the entire eastern Pacific north of, approximately, latitude $40 \mathrm{~N}$. In association with this surface pattern, a closed cyclonic circulation existed at all levels up to and including the 300 -mb level over the extreme northern portion of the Gulf of Alaska (see Fig. 2a').

Satellite picture sequences were obtained on Orbits

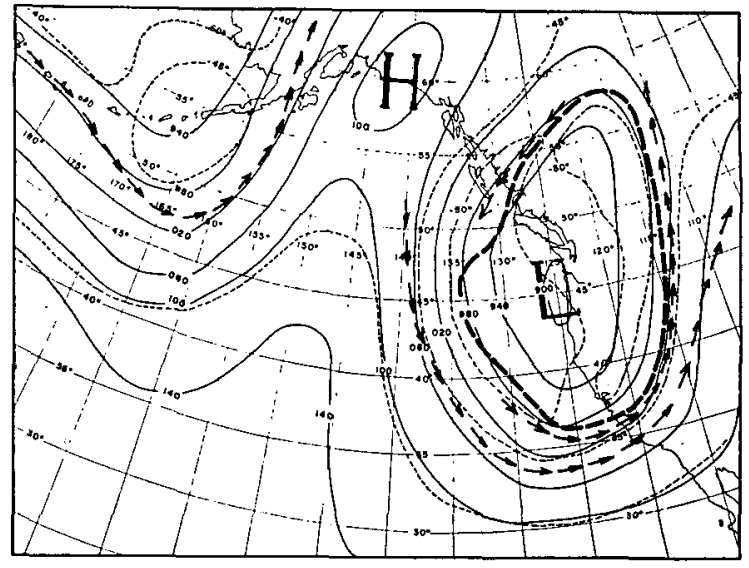

FIG. $2 d^{\prime}$

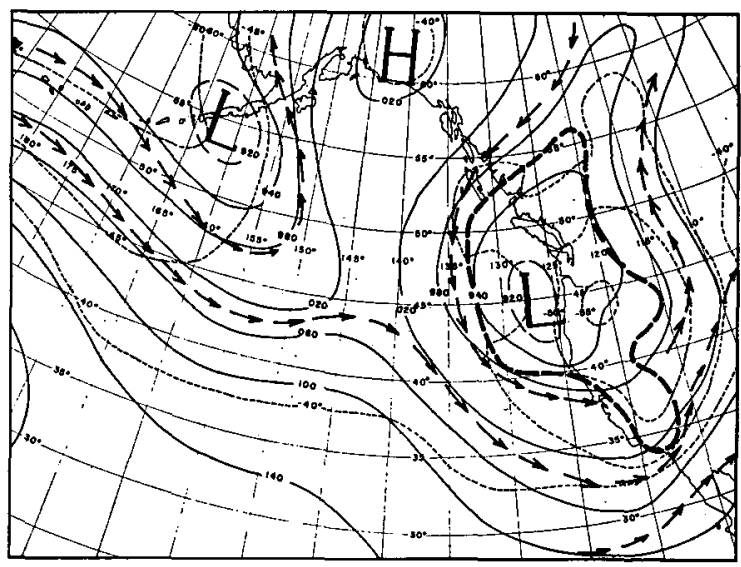

FIG. 2e'

0703, 0704, and 0705 over the eastern Pacific Ocean on 19 May 1960. The gross features of the cloud patterns associated with the storm at this stage in its development are shown in Fig. 3. Particularly interesting cloud features included:

(1) An extensive, bright cloud band consisting of stratiformtype clouds with bright cumuloform elements embedded along its length (see Figs. 3a and $3 \mathrm{~d}$ ).

(2) Cellular clouds between $45 \mathrm{~N}$ and $50 \mathrm{~N}$ latitude, arranged in two, ill-defined, spiral patterns (see Figs. $3 \mathrm{~b}$ and $3 \mathrm{c})$.

The radarscope data for 0000 GMT 20 May show that weak, convective showers existed in a broken line along the extensive, bright, cloud band. ${ }^{7}$ This precipitation

${ }^{7}$ Radar echoes outside the area of radarscope coverage near $44 \mathrm{~N}$, $128 \mathrm{~W}$ were extrapolated by time section procedures (Blackmer, 1957). Briefly, this process consists of extrapolating in space the echo pattern observed at a fixed point. This is accomplished by displacing the echo pattern observed at a given time by a distance and in a direction appropriate to the prior velocity of motion of the pattern. 


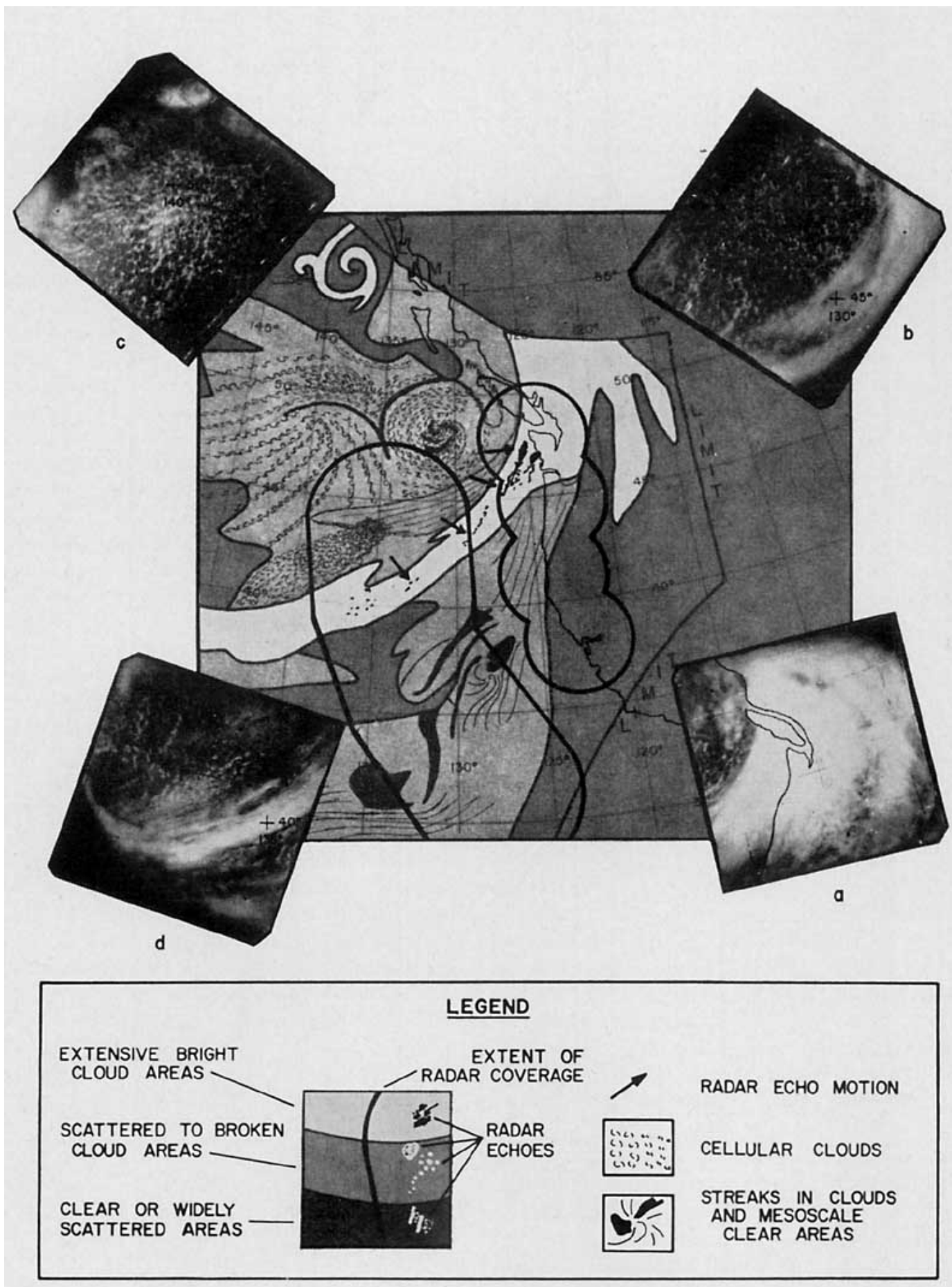

FIG. 3. Schematic representation of cloud patterns observed on TIROS I orbits 0703, 0704, and 0705; radarscope data for approximately 0000 GMT 20 May 1960; and selected satellite pictures illustrating cloud features mentioned in the text. 
pattern is frequently seen along the cold frontal portion of occluded frontal systems in this area of the Pacific Ocean (Nagle, 1960) ${ }^{8}$, although usually in a more continuous line. Since in this case the bright cloud band and the radar echoes both corresponded well to the analyzed position of the surface cold front, we will henceforth refer to these clouds as the frontal band. In viewing the original radarscope film from the stations in Oregon and Washington, the extent of the precipitation along the front was observed to have increased and to have changed in character near the apex of the analyzed surface warm-frontal position from showery to mixed showers and stratiformtype precipitation. Surface reports indicate that the precipitation in advance of the warm front over Vancouver Island and the state of Washington was more extensive than is shown by the radar data over this area. The sparsity of echoes in this area may be attributed to the limited capabilities of the 23 -cm radar equipment at Neah Bay, Wash., to detect light precipitation.

The coverage provided by the $10-\mathrm{cm}$ airborne radar extended some $400 \mathrm{mi}$ into the post-cold frontal region of the cyclone. The absence of echoes in this sector of the storm indicates that there was no precipitation associated with the clouds observed by the satellite over this area at this time. The absence of showers in the immediate postcold frontal region has been noted in other radar studies (see footnote 3 ) of maritime precipitation patterns and may, perhaps, be characteristic of oceanic storms.

\section{B. 0000 GMT 21 May 1960}

By 000021 May, the Arctic air advancing behind the occluded frontal system had moved rapidly southeastward and dominated the entire eastern Pacific north of the San Francisco Bay area (see Fig. 2b). The center of the closed circulation at the 300-mb level (Fig. 2b') had moved to the Vancouver Island region, and the "cuttingoff" process of this low pressure area was complete.

Satellite pictures over the area of interest were obtained on only one orbit (0720) on 21 May. The schematic representation of the clouds observed is shown in Fig. 4.

The frontal cloud band was now oriented generally in a north-to-south crescent across British Columbia, western United States and then extended through central California to the picture limit. The trailing edge of this extensive stratiform band terminated abruptly, and the cloud forms behind it (over the land) changed to mixed stratiform and cumuloform type (see Fig. 4a). The radarscope data show that, in this sector of the

\footnotetext{
8 Nagle, R. E., and R. H. Blackmer, Jr., 1961: Comparisons of radar precipitation and satellite cloud observations. Sci. Rpt. No. 2, Contract AF 19(604)-5982, Stanford Research Institute, Menlo Park, Calif., $38 \mathrm{pp}$.
}

frontal cloud band, the precipitation was very weak and disorganized. In the central California region, precipitation was not detected by the $23-\mathrm{cm}$ radar near San Francisco; if precipitation was present in this portion of the front, it was very light.

Over the ocean the cellular cloud pattern, which apparently terminated south of $40 \mathrm{~N}$ latitude, covered a large area within the Arctic air mass. The cells within this pattern showed considerably more organization than when viewed $24 \mathrm{hr}$ previously, and they were aligned as part of a definite spiral cloud vortex located near $47 \mathrm{~N}, 135 \mathrm{~W}$ (see Fig. 4b). The cloud patterns surrounding this cloud vortex suggest that there was an extensive circulation associated with this system. This was evident in the bright, irregularly shaped cloud patches to the north of the vortex (see Fig. 4c) and the extensive, "streaky" cloud mass near 50N, 145W (see Fig. 4 d), both of whose orientations suggest they were an integral part of the cloud vortex. Precipitation within the cellular clouds consisted of weak and widely scattered showers organized in a pattern comparable to the spiral seen in the cloud observations (see the scattered line of echoes between 40 and $45 \mathrm{~N}$ and between 130 and $135 \mathrm{~W}$ on Fig. 4). The characteristics of the radar echoes detected along the coast, however, indicated that these showers were of heavier intensity than the showers which were occurring further to the west but they did not show any organized pattern. The motion of these echoes was, as would be expected in such a cold air mass, from the west-northwest or northwest. The motion of the echoes detected by the airborne station near $45 \mathrm{~N}$ could not be deduced because of the diffuse character of the precipitation and the motion of the aircraft.

An interesting and important feature of this cloud vortex is its location; the pattern was embedded in what was analyzed as a deep, moderate-to-strong, northwesterly flow regime that extended from the Aleutian Islands to the coast of Northern California. Examination of available surface and upper air data for 0000 GMT 21 May 1960 gave no clear indication of a related circulation in the wind field at any level in the same region. The significance of this cloud vortex becomes apparent when developments which occurred during the succeeding $24 \mathrm{hr}$ are considered.

\section{0000 GMT 22 May 1960}

The surface synoptic chart for 0000 GMT 22 May, Fig. 2c, shows that the occluded frontal system had continued to move eastward and was now located outside the area of interest, over the Rocky Mountains. The surface pressure and wind reports over the farwest were so confused as to preclude any consistent largescale analysis. The situation aloft was still well defined, and continuity from previous maps could be followed. The 300-mb low pressure center had continued to move slowly southward, and at this time was located near 


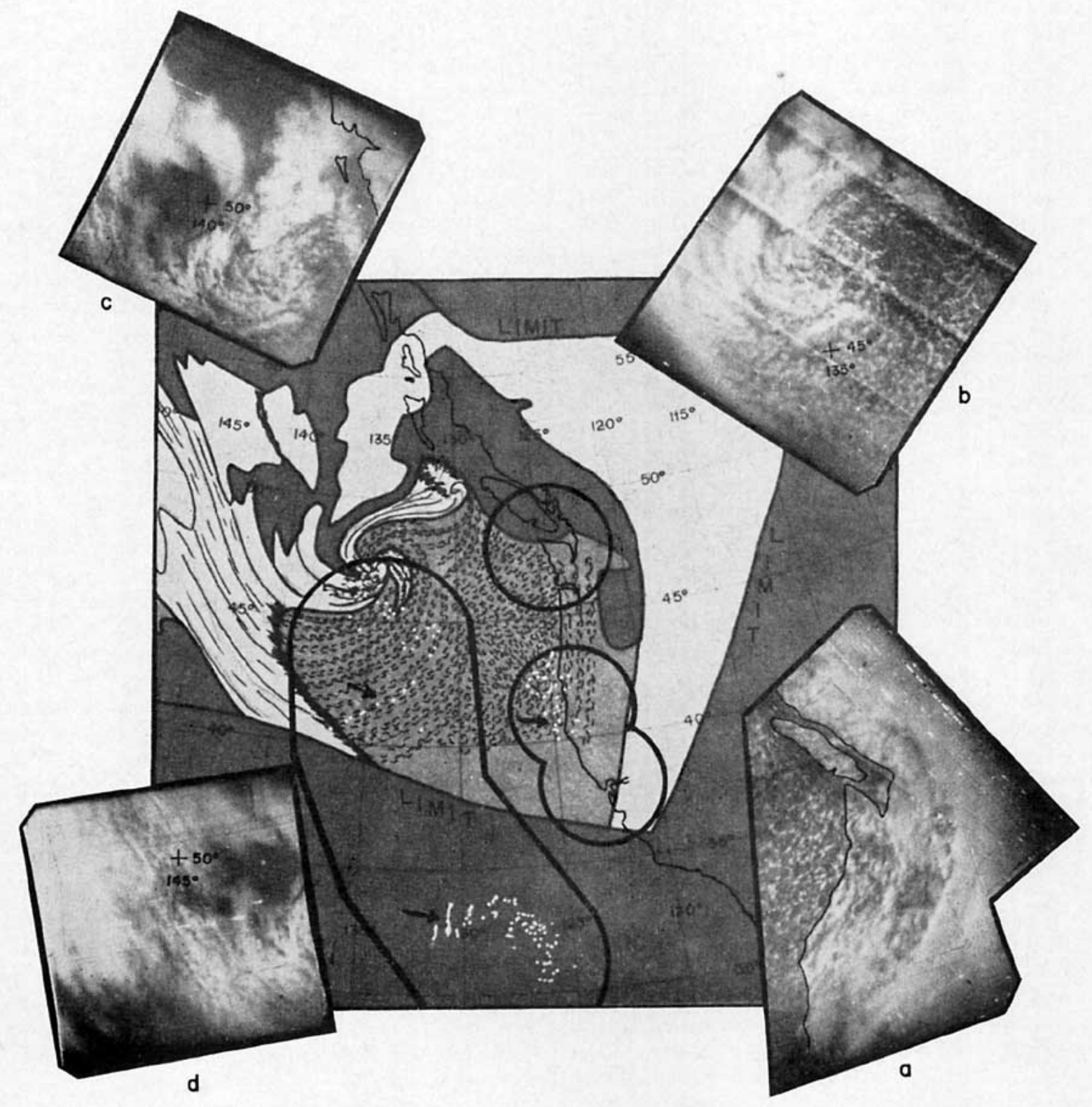

FIG. 4. Schematic representation of cloud patterns observed on TIROS I orbit 0720 ; radarscope data for approximately 0000 GMT 21 May 1960; and selected satellite pictures illustrating cloud features mentioned in the text. (Legend of Fig. 3 also applies to this figure.) 
$45 \mathrm{~N}, 125 \mathrm{~W}$ (see Fig. $2 \mathrm{c}^{\prime}$ ). The central Pacific ridge at the $300-\mathrm{mb}$ level had attained its maximum amplitude at this time and was reflected by the strong high pressure cell on the surface chart.

Picture sequences from four orbits $(0731,0732,0733$ and 0734) were available for analysis on 22 May; the clouds observed on these orbits are shown in Fig. 5 in the same format as those on the two previous days of this study. The frontal cloud band, now over the interior of the United States, had become desiccated by its traverse over the Rocky Mountains and had lost much of the consistency it exhibited in pictures taken on the previous day's orbits. Over the southwest this band was discontinuous but over the ocean along latitude $31 \mathrm{~N}$ it could still be recognized as an organized system (see Fig. 5a).

The gross cloud pattern associated with the cyclone off the Washington Oregon coast now had the appearance of a huge spiral centered near the location of the $300-\mathrm{mb}$ low-pressure center. The relatively minor changes that had occurred in the synoptic patterns during the preceding 24 -hr period would suggest that this cloud system was a further development of the cloud vortex seen 24 and $48 \mathrm{hr}$ previously at $47 \mathrm{~N}, 135 \mathrm{~W}$ and $48 \mathrm{~N}, 142 \mathrm{~W}$, respectively. This pattern could now, for the first time, be associated with the low pressure system which existed at the middle and upper levels of the troposphere off the coast of Washington. Analyses of the air mass structure of the cyclone showed that, in the main, the orientation of the cloud patterns could now be used as a reasonable indicator of the circulation associated with the low pressure area. The cloud patterns (and clear areas) indicated that the circulation was drawing in several different air masses in the configuration shown in diagrammatic form in Fig. 6. The $500-\mathrm{mb}$ temperatures and tropopause heights are one method of characterizing air masses, especially with reference to wind fields (Staff members of the Department of Meteorology, University of Chicago, 1947). This method is used below. Upper air soundings for 0000 GMT 22 May 1960, illustrating the structure of the various air masses involved in the storm, are shown around the periphery of Fig. 6 . The specific air masses consisted of the following:

(1) Maritime Arctic air which constituted the basic core of the storm. This air mass was characterized by a very low tropopause, $400 \mathrm{mb}$ or lower, and $500-\mathrm{mb}$ temperatures as low as $-35 \mathrm{C}$. The structure of this air mass is illustrated by the Medford, Oreg., sounding (Station 597, lower right of Fig. 6). The cellular clouds which are shown in Figs. $5 \mathrm{a}, 5 \mathrm{~b}, 5 \mathrm{c}$, and $5 \mathrm{~g}$ were the basic cloud forms associated with this air mass.

(2) Maritime Polar air which was entering the storm from a northeasterly direction across British Columbia. The sounding at Port Hardy, Vancouver Island (Station 109, upper right of Fig. 6) typifies this air mass which had been lifted by the advancing Arctic outbreak and was considerably modified by a long trajectory over the continent. The temperature at the $500-\mathrm{mb}$ level was approximately $-25 \mathrm{C}$, while the height of the tropopause was found near the $285-\mathrm{mb}$ level. Clouds associated with this air mass are shown in Fig. 5d.

(3) Dry Maritime Polar air which was entering the system from a northerly direction across the eastern part of Alaska and through the northern Gulf of Alaska. An extensive clear slot, shown in Fig. 5e, reflects the injection of this air into the storm. The sounding at Yakutat, Alaska (Station 361, at the top of Fig. 6) shows the characteristic structure of this air mass, which had a 500-mb temperature of about $-18 \mathrm{C}$ and a tropopause height near $240 \mathrm{mb}$.

(4) Warm Maritime Polar air which was entering the system from a northwesterly direction from the region to the south of the Aleutian Islands. Ocean Station "PAPA," as evidenced by the characteristics of the sounding from this station shown in the upper left of Fig. 6, was in this air mass. A high tropopause near $185 \mathrm{mb}$ typified this air mass while the $500-\mathrm{mb}$ temperature was in the vicinity of $-12 \mathrm{C}$. Clouds associated with this air mass are shown in Fig. $5 f$.

(5) Maritime Tropical air which existed along the southern periphery of the storm, but which was apparently not active in the storm. Tropopause heights in this air mass were found near the $170-\mathrm{mb}$ levels while $500-\mathrm{mb}$ temperatures persisted near $-12 \mathrm{C}$ (see sounding from Ocean Station "NAN" at the bottom of Fig. 6).

Although air-mass boundaries were found at differing levels over the area of radarscope coverage, the data suggest that the precipitation which was occurring was predominantly associated with instability conditions within the Arctic air. This activity was in the form of scattered-to-broken lines of showers, which at this time were confined almost exclusively to the area where cellular clouds were observed. The motion of these echo areas corresponded well with the general pressure pattern and the configuration of the spiral cloud vortex.

It might seem paradoxical that showers were not detected at airborne Stations 7 and 9 at this time; however, subsequent to the satellite observations, showers were detected at these stations. The sequence of radarscope developments at Station 7 is shown in Fig. 7 with a perspective gridded frame from Orbit 0732 showing the cellular cloud pattern associated with these showers. The coverage provided by the airborne radar at Station 7 is also shown on the gridded picture. An area of wellorganized, bright cellular clouds has been extrapolated to the south-southeast for $9 \mathrm{hr}$ at the speed of the 700$\mathrm{mb}$ level wind, and its position at 0700 GMT $(2100$ Local) 22 May 1960 is indicated by the area circumscribed by the dashed curve. Echoes first appeared at Station 7 some two hours, 0000 GMT (1400 Local), after the satellite cloud observations were obtained. Two hours later, 0200 GMT (1600 Local), a recognizable 


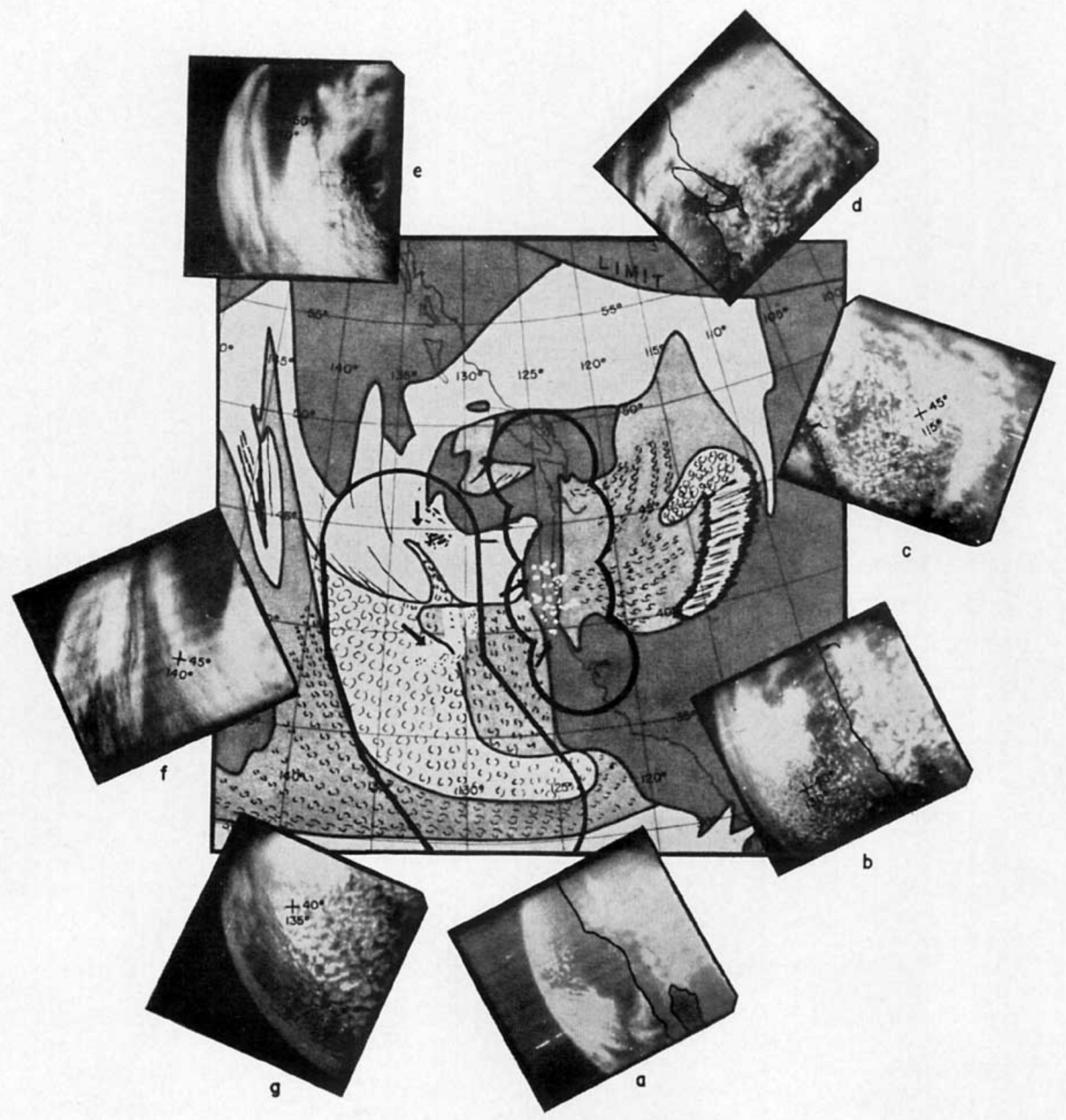

FIG. 5. Schematic representation of cloud patterns observed on TIROS I orbits $0731,0732,0733$, and 0734 ; radarscope data for approximately 0000 GMT 22 May 1960; and selected satellite pictures illustrating cloud features mentioned in the text. (Legend of Fig. 3 also applies to this figure.) 

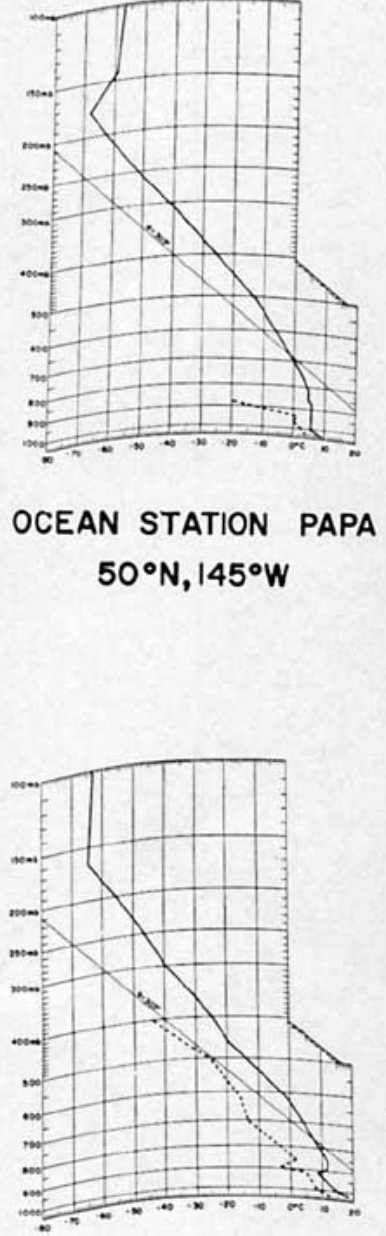

OCEAN STATION NAN $30^{\circ} \mathrm{N}, 140^{\circ} \mathrm{W}$

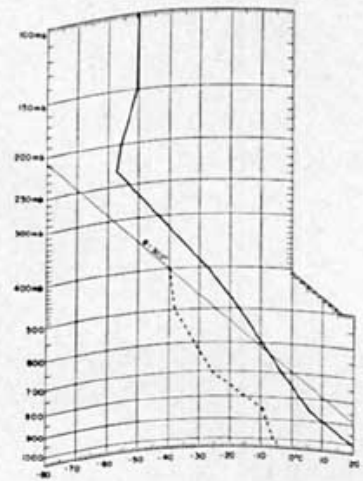

YAKUTAT, ALASKA

STATION 36I

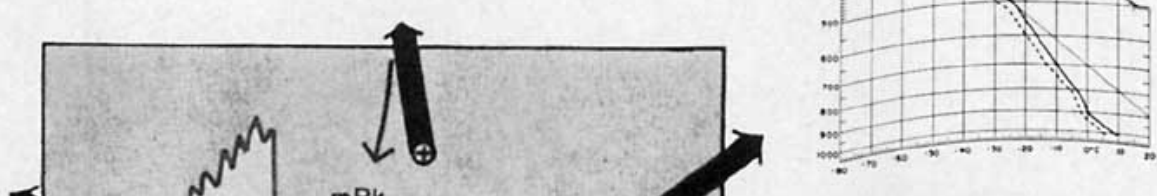

PT. HARDY, BR. COLUMBIA

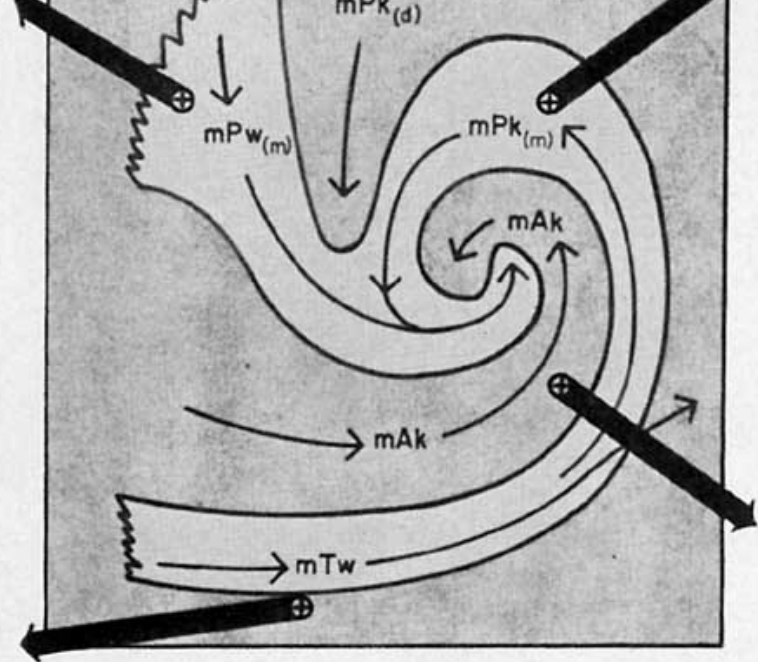

$$
\begin{array}{|lll}
\hline & \text { LEGEND } & \\
\text { P-POLAR } & \text { m-MARITIME } & \text { (d) -DRY } \\
\text { T-TROPICAL } & k \text { - COLD } & \text { (m)-MOIST } \\
\text { A - ARCTIC } & \text { w-WARM } & \oplus \text { - } \begin{array}{c}
\text { station } \\
\text { location }
\end{array}
\end{array}
$$
STATION 109
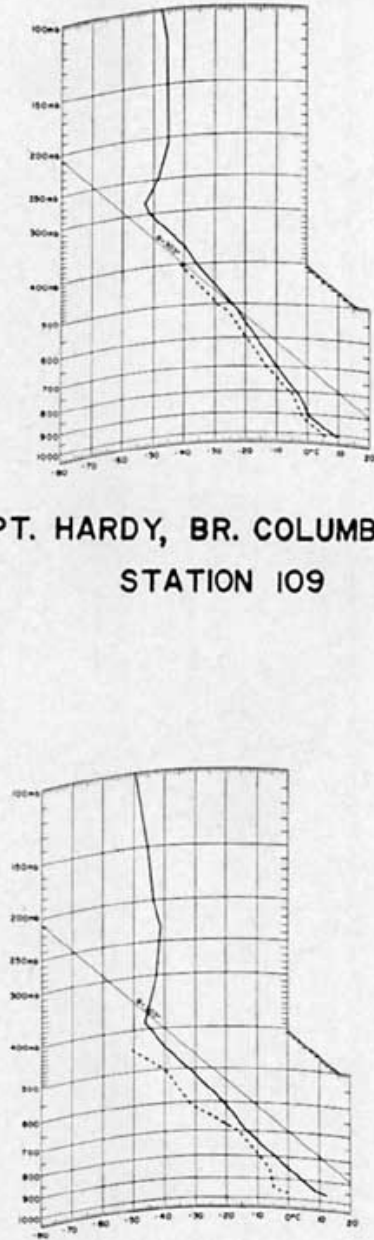

MEDFORD, OREGON

STATION 597

FIG, 6. Diagrammatic representation of the air masses involved in the storm and radiosonde data illustrating the structure of the air masses. 


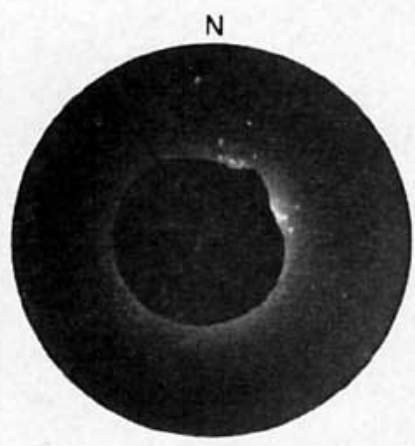

b

AIRBORNE STATION 7
0200 GMT 22 MAY 1960

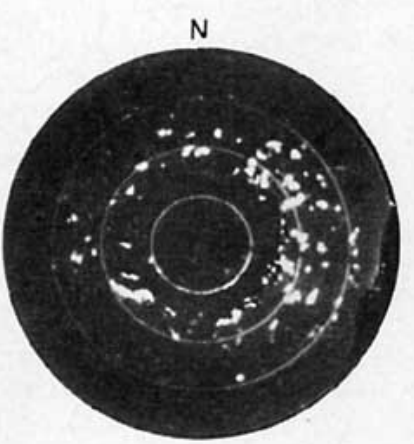

c

AIRBORNE STATION 7 0700 GMT 22 MAY 1960

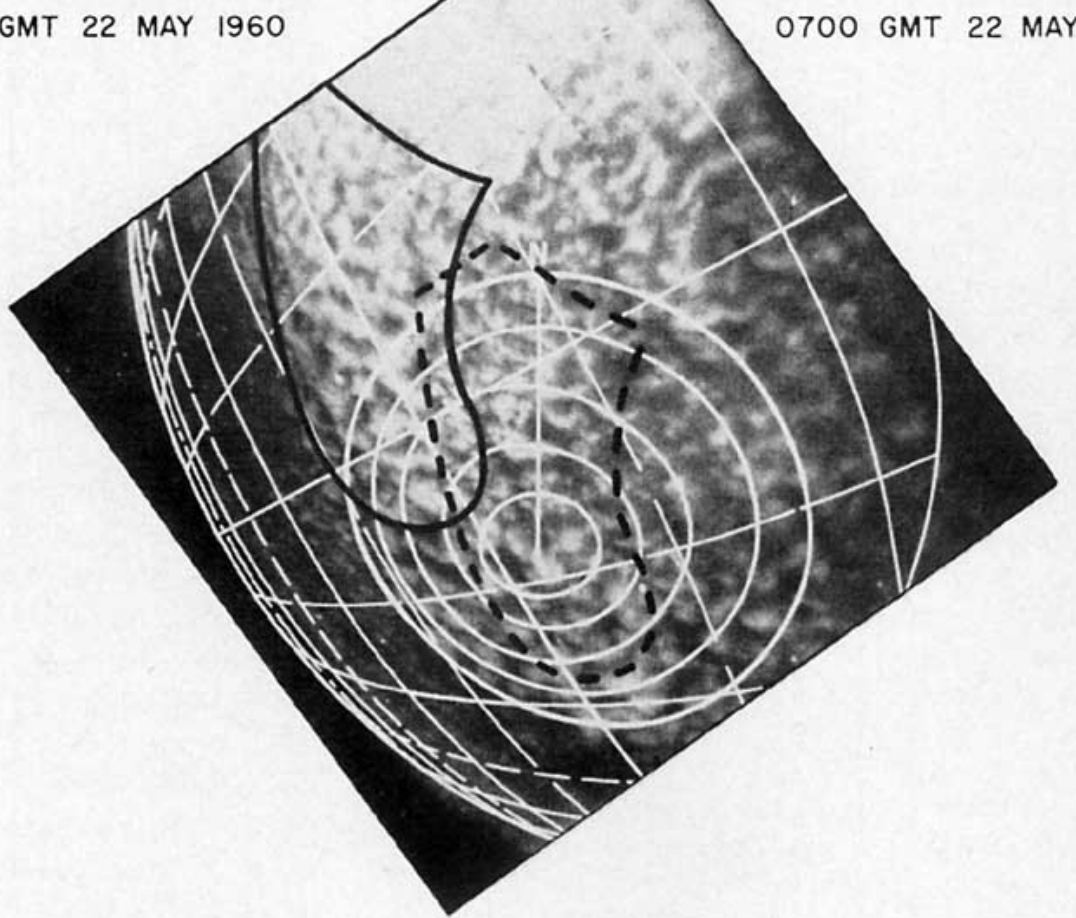

a

FRAME NUMBER 10

TIROS I ORBIT 0732

2135 GMT 2I MAY 1960

FIG. 7. Radarscope photographs from airborne station 7 showing the development of echoes in the cellular cloud pattern observed on TIROS I orbit 0732: (a) Perspective-gridded TIROS I picture, frame No. 10 orbit 0732, tape with radarscope coverage from airborne station 7 superimposed; (b) 0200 GMT 22 May 1960 airborne station 7 radarscope data; (c) 0700 GMT 22 May 1960 airborne station 7 radarscope data (S-band radar, 200-mi range, aircraft altitude $-6000 \mathrm{ft}$ ). 
pattern having the appearance of a circular "ring" of weak echoes some $60 \mathrm{mi}$ in diameter was discernible on the radarscope. Within the succeeding 5 -hr period, the echo pattern intensified and moved to the southeast until 0700 GMT (2100 Local) when these developments reached their maximum intensity, with ring-shaped echo areas covering the radarscope out to about $150 \mathrm{n} \mathrm{mi.}{ }^{9}$ Notice, in this case, how the extrapolated position of the bright, cellular cloud area is in good agreement with the echo activity at $0700 \mathrm{GMT}$ and, more significantly, notice that the showers tend to mirror (but to a lesser degree) the configuration of the cloud elements. When the radarscope film was viewed in cinémotion, the echo pattern was seen to expand and intensify at a greater rate than could be accounted for solely by advection of showers into the area of radar coverage. The fact that these developments occurred shortly after local sunset indicates that shower activity associated with this particular type of cellular cloud pattern may be subject to diurnal effects. Of further significance is the life span of these showers; even the smaller echoes $(3-5 \mathrm{mi}$ in diameter) were observed to have persisted for at least 2 hours. This is in contrast to the duration of continental air-mass showers, which seldom last over 30 minutes (Battan, 1953).

\section{0000 GMT 23 May 1960}

The surface synoptic chart for 0000 GMT 23 May 1960, Fig. 2d, showed very little change from the chart $24 \mathrm{hr}$ previous. The occluded frontal system had moved far into the continental United States, bringing the entire western section of the country under the influence of the Arctic air mass. At the 300-mb level, Fig $2 d^{\prime}$, the center of the low-pressure area had remained practically stationary off the coast of Washington. The northern part of the central Pacific ridge had split off, with a high pressure cell having formed over southern Alaska.

Schematic representations of the cloud patterns observed on Orbits 0746 and 0747 on 22 May are shown in Fig. 8. Portions of the cloud shield in advance of the occluded section of the frontal system were still visible inside the area of consideration but, for the most part, the clouds associated with the front either had moved considerable distances inland or had dissipated. The spiral pattern of the storm was even more distinct at this time than on previous days, especially in the cumuloform cloud bands off the Oregon Coast (see Fig. 8b). The extensive clear area associated with the dry maritime polar air mass (see Fig. 8c) is of particular interest.

\footnotetext{
"Heavy "sea clutter" was detected by these airborne radar stations to ranges up to about $80 \mathrm{mi}$; these pictures have been retouched to remove these non-hydrometeor echoes, which gives the appearance of an echo-free area around the center of the scope. Some precipitation echoes undoubtedly have also been obliterated by this process.
}

Forty-eight hours earlier this clear area was observed over the northern part of the Gulf of Alaska (see Fig. $4 \mathrm{c}) ; 24 \mathrm{hr}$ later it was seen as an organized, north-south oriented slot along longitude 140W (see Fig. 5e); in the following $24 \mathrm{hr}$ the clear area continued its southerly plunge as a persistent feature and became more extensive than on the previous two days. The configuration of the clouds at the southern end of this clear slot (near $37 \mathrm{~N}, 138 \mathrm{~W}$ ) at $0000 \mathrm{GMT} 23$ May strongly suggests that the southerly movement of this dry air mass was severing the flow of the warm Maritime Polar air which had been entering the storm system from the central Pacific (see Fig. 8d). If this indeed was the case, then we may be "seeing" in the cloud patterns dynamic processes involved in the energy and moisture budget of such storm systems.

In addition to the major cloud vortex associated with the storm, two minor cloud vortices could now be seen in the wide-angle camera pictures (see Fig. 8a and 8e). These cloud vortices, whose centers were located near $37.5 \mathrm{~N}, 132 \mathrm{~W}$, and near $35.5 \mathrm{~N}, 137.5 \mathrm{~W}$, eluded detection by conventional analyses. In light of the subsequent radar and cloud pattern developments, observations of these cloud vortices were of importance. In the vicinity of the easternmost of the minor vortices, extensive shower activity was occurring, with the showers aligned in the same general orientation as the cellular clouds seen in this area on the satellite photographs. In contrast, the shower activity further south was light and widely scattered. The motion of both these echo areas was from the west-northwest but, again, the difficulties inherent in the airborne radar observations preclude a detailed echo motion study of the precipitation cells in the vicinity of the minor vortex.

Along the coast, extensive and heavy shower activity was occurring, as revealed by the echoes detected at the Klamath Falls radar installation. Intermittent showers had been occurring at this station since shortly after the frontal passage on 20 May. The relative intensity and areal extent of the showers at this time were increasing, and heavy precipitation continued throughout the day. The relative motion of these echoes was definitely cyclonic, and one small (30 mi in diameter) spiralrotating precipitation center moved onto the Oregon coast at about 0600 GMT on 23 May. ${ }^{10} \mathrm{It}$ is interesting to note that the precipitation at this station, which was in the region where warm Maritime Polar air was com-

\footnotetext{
10 At the time of the satellite pictures, this rotating echo area was beyond the range of the Klamath Falls radar installation. Extrapolating the center of rotation back along its direction of motion would place the center in the vicinity of the echo activity detected at airborne Station No. 7 at the time coincident with the satellite pictures. Unfortunately, a determination of rotation in the echoes detected at Station No. 7 was not possible because of the motion of the airborne radar platform.
} 


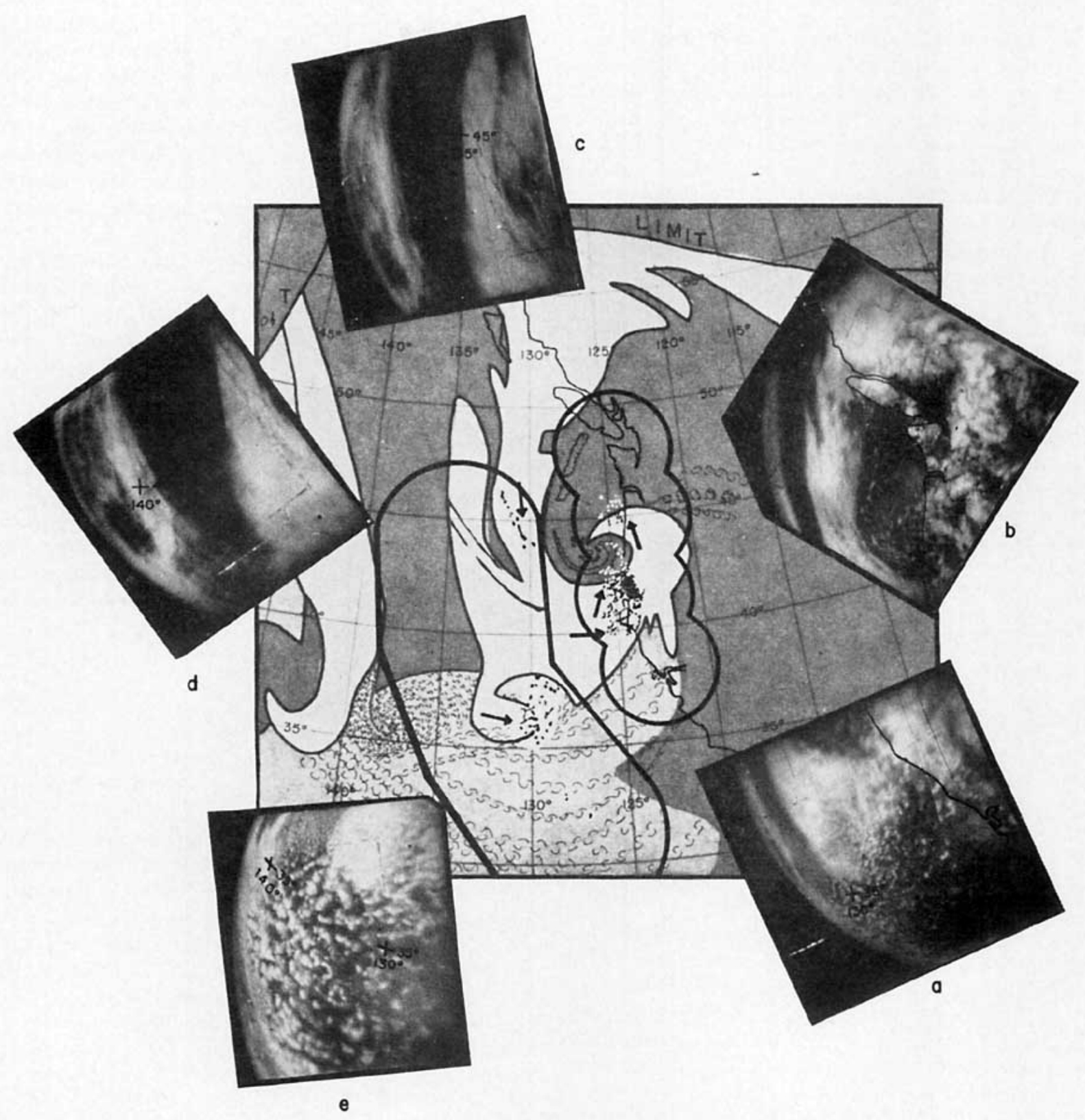

FIG. 8. Schematic representation of cloud patterns observed on TIROS I orbits 0746 and 0747 ; radarscope data for approximately 0000 GMT 23 May 1960; and selected satellite pictures illustrating cloud features mentioned in the text. (Legend of Fig. 3 also applies to this figure.)

ing into confluence with the recirculated Arctic and cold Maritime Polar air masses (see Fig. 6), was more persistent and of heavier intensity (as determined by radar echo appearances) than that detected by any other radar station along the coast. Thus, one might expect that, even in the absence of distinctive surface frontal patterns, regions where organized cloud systems are evident in satellite pictures should be suspected as being related to air-mass confluences and accompanied by the attendant weather. 


\section{E. 0000 GMT 24 May 1960}

By 0000 GMT 24 May, the synoptic patterns indicated that the strong blocking situation was breaking down and that zonal flow was once again being initiated. The surface chart, Fig. 2e, showed a closed low-pressure center located over the Columbia River region of the state of Washington. The strong ridge which had been present along $145 \mathrm{~N}$ longitude $24 \mathrm{hr}$ previously had greatly weakened. At the $300-\mathrm{mb}$ level (Fig. 2e'), the low pressure area had persisted off the WashingtonOregon coast, but in the central Pacific the upper level ridge had split into two separate high pressure cells, with the Polar Westerlies having returned along latitude $45 \mathrm{~N}$.

Satellite pictures on this fifth and last day of the study were obtained on three orbits $(0761,0762$ and 0763). The gross features of the clouds, shown in Fig. 9, still maintained sufficient identity to allow continuity from previous days' orbits to be followed. The spiral nature of the cloud pattern associated with the storm was still evident, but several significant changes had occurred during the prior 24 -hr period. Within the inner band of the spiral, the clear or widely scattered area over the ocean had greatly increased (see Fig. 9b). This increase can be attributed to a combination of sustained subsidence within the Arctic air mass and the recirculation of the Arctic air around the stationary low pressure cell. This cold air mass, initially of maritime origin, advected over the continent and returned once again over the ocean from a northeasterly direction, completing a loop around the low-pressure center. The absence of both the extensive cellular cloud pattern and precipitation in this recirculated air indicates that it was considerably modified by its long passage over the warmer ocean and land masses.

By comparison, the width of the clear slot, which had been moving rapidly southward along longitude $135 \mathrm{~W}$, had diminished greatly and was almost pinched off into two separate sections near $47.5 \mathrm{~N}, 149 \mathrm{~W}$ (see Fig. 9c). This may be accounted for by a counterclockwise rotation of the spiral cloud band associated with the system off the Washington coast, and the merger of this cloud system with the cloud shield advancing in front of the new storm system further to the west. Shower activity existed within the westward rotating band, but it was weak. Extensive, heavy, stratiform-type precipitation, however, was detected within the cloud shield associated with the new storm system advancing from the west.

The dense cloud cover which existed over the central California region (see Fig. 9a) is worthy of note. Counterclockwise rotation of the cloud pattern of $0000 \mathrm{GMT}$ 23 May 1960 by some 80 deg around the center of the spiral cloud vortex would bring the minor cloud vortex (which $24 \mathrm{hr}$ earlier was located at $37.5 \mathrm{~N}, 132 \mathrm{~W}$ ) to the position where the clouds over central California were now located. The radarscope data during this same period showed that precipitation in successive heavy bands had been moving onto the continent between the San Francisco Bay area and northern Oregon. The peak of sustained precipitation activity correlates well with the time of passage of the extrapolated rotational path of the minor cloud vortex. At the time of the satellite cloud observations, the extent of the precipitation in this area was greatly reduced, but heavy showers were still detected by the radar installations at Klamath Falls and Mt. Tamalpais.

The cellular cloud pattern, so prominent on the previous days of this study, was still in evidence, but it gave the appearance of being in a decaying stage. The continued presence of showers indicated that, in spite of the reduction in the organization of the cellular clouds, active convection was still occurring in the Arctic air.

With the advance of the new occluded system from the west, the synoptic pattern changed rapidly to a zonal flow pattern again. The satellite observations and radar data that were available on succeeding days showed that, with the return of the zonal flow aloft, the storm rapidly lost its distinctive patterns and was absorbed by the new system moving in from the west.

\section{Summary}

This study has discussed relationships which existed between precipitation and satellite-observed cloud patterns during five days within the life cycle and within certain sectors of a maritime cyclone. The cloud patterns associated with this storm exhibited features which, since the advent of meteorological satellites, have also been considered characteristic of occluded vortices: (1) a spiral vortex structure in the gross cloud pattern, (2) an extensive area of cellular type clouds, (3) a widespread rift (clear area) in the main cloud sheet, and (4) an extensive organized cloud band in juxtaposition with the analyzed surface frontal position.

Glaser ${ }^{11}$ has suggested that the evolution of the spiral cloud pattern can be related to the classic stages of development of the open-wave cyclone. This implies a direct association of the cloud patterns with the surface fronts. In our study, cloud photographs revealed a vortex where the amount and content of synoptic data did not permit the analyst to draw a surface front. These data, however, were adequate to establish a clear association between the cloud vortex and a pressure vortex in the middle and upper troposphere. This cloud vortex and the associated rainfall, as evident from radarscope data, were present at least 24 hours prior to any other synoptic indication of the existence of such a system.

${ }^{11}$ Glaser, A. H., 1961 : TIROS meteorology. Final Rpt. Contract AF 19(604)-5581, Allied Research Associates, Inc., Boston, Mass., 109 pp. 


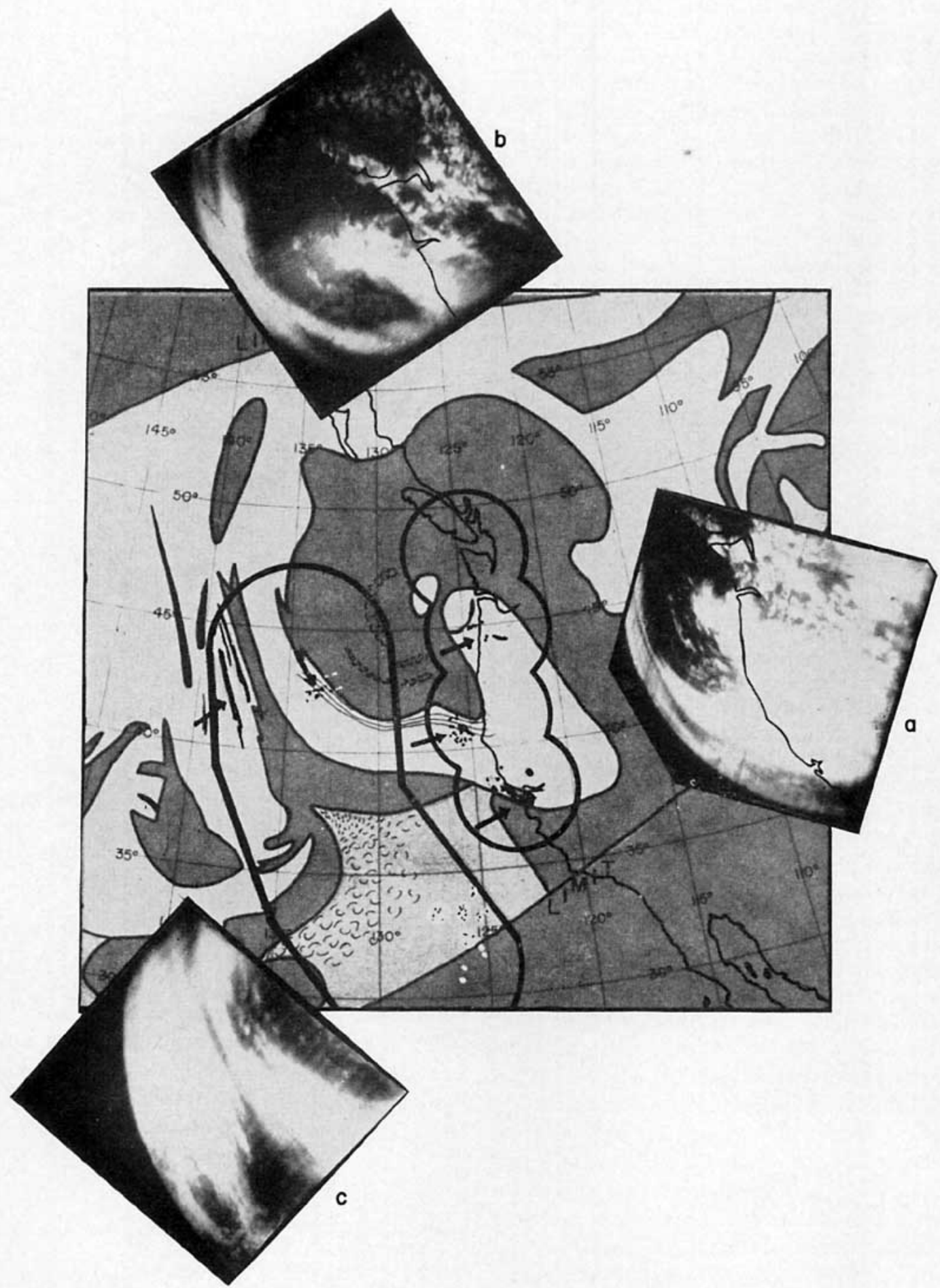

Fig. 9. Schematic representation of cloud patterns observed on TIROS I orbits 0761,0762 , and 0763 ; radarscope data for approximately 0000 GMT 24 May 1960; and selected satellite pictures illustrating cloud features mentioned in the text. (Legend of Fig. 3 also applies to this figure.) 
In view of the further evidence of the characteristicness of the cloud patterns associated with extratropical oceanic cyclones which this study has provided and the uniformity of the surface boundary conditions over the oceans, it would be reasonable to postulate that the distribution of precipitation associated with the cloud patterns of this storm could be characteristic of precipitation-to-cloud relationships in other maritime extratropical cyclones. A model for the distribution of radar precipitation echoes around an occluded oceanic cyclone derived from examination of extensive radarscope film records from airborne, ship, and coastal radar stations in the eastern Pacific Ocean is presented in Fig. 10. This model differs from the continental precipitation model presented by Ligda et al. ${ }^{12}$ only by the presence of the extensive convective shower activity observed in maritime storms. The different types of precipitation, illustrated in diagrammatic form in Fig. 10, are shown in Fig. 11 as detected by an 8-cm wide-beam radar set. In the study presented in this paper, radar data were not available in the northeast quadrant of the storm, and therefore little of the extensive stratiform type precipitation which accompanies such cyclones could be presented for comparison with the satellite cloud pictures.

This study strongly re-emphasizes the fact that at any particular instant of time a very low percentage of clouds precipitate. Even when organized cloud patterns (on all scales) are evident, precipitation occurs only in very limited areas of a storm and under very restricted meteorological conditions, as given below.

The cloud forms and precipitation shown along the cold frontal section of the occluded frontal system (see Fig. 3) are characteristic of Pacific Ocean cyclones when close to the west coast of North America. When cellular clouds are present in the immediate post-cold frontal region, these clouds are usually of non-precipitating nature (see Fig. 3); however, such cellular clouds associated with the core of a low level cold outbreak do precipitate when the cold air is heated from below (see Fig. 4). Showers which develop in association with these cellular clouds show (a) the same distribution as the cloud elements, (b) a diurnal cycle (see Fig. 7), and (c) a life cycle which is much longer than continental airmass showers. Shower activity can be expected from such clouds even when they are diffuse or in a dissipating stage (see Fig. 9). Cellular clouds may also be organized into spiral patterns in regions where a surface pressure vortex is either absent or too small to be defined by the network of observing stations. Precipitation patterns associated with such cloud vortices show a comparable orientation (see Fig. 4).

${ }^{12}$ Ligda, M. G. H., S. M. Serebreny and R. E. Nagle, 1961: Weather radar systems research. Final Rpt. Contract AF 19(604)3067, Stanford Research Institute, Menlo Park, Calif., 82 pp.

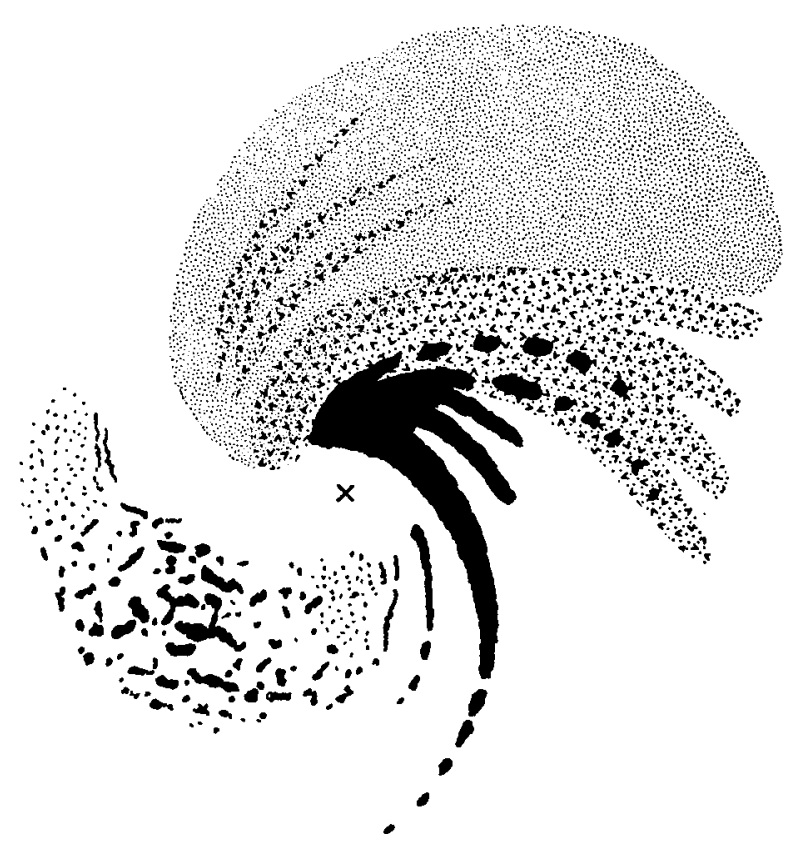

FIG. 10. Schematic model of the radar precipitation echo distribution around an occluded maritime cyclone. Light stippled area denotes continuous stratiform type precipitation; checked area, ragged patches of stratiform type precipitation; solid areas, convective type precipitation; $x$, pressure vortex center.

From air-mass considerations, it appears the cloud patterns can be used as a reasonable indicator of the airmass structure of a cyclone (see Figs. 5 and 6); minor cloud vortices may develop along regions of confluence of differing air masses. These minor vortices show movement around the periphery of the major spiral cloud band which appears to be related to rotation in the gross cloud pattern. Heavy, persistent and extensive precipitation was observed with such minor vortices with a patterned organization and motion similar to the cloud patterns.

Acknowledgment. The authors would like to express their gratitude to the hundreds of Air Defense Command personnel who participated in the radarscope photography program. Their cooperation, suggestions and.interest were paramount to the successful collection of the high quality photorecords.

\section{REFERENCES}

Battan, L. J., 1953: Duration of convective radar cloud units. Bull. Amer. meteor. Soc., 34, 327-28.

Blackmer, R. H., Jr., 1957: The use of radar data in mesometeorological annalysis. Proc. Sixth Weather Radar Conf., Boston, Amer. Meteor. Soc., 207-213.

Bristor, C. L., and M. Ruzecki, 1960: TIROS I photographs of the midwest storm of April 1, 1960. Mon. Wea. Rev., 88, 315-326.

Fritz, S., 1960: Meteorological observations from satellites. New Scientist, 10, 504-507. 


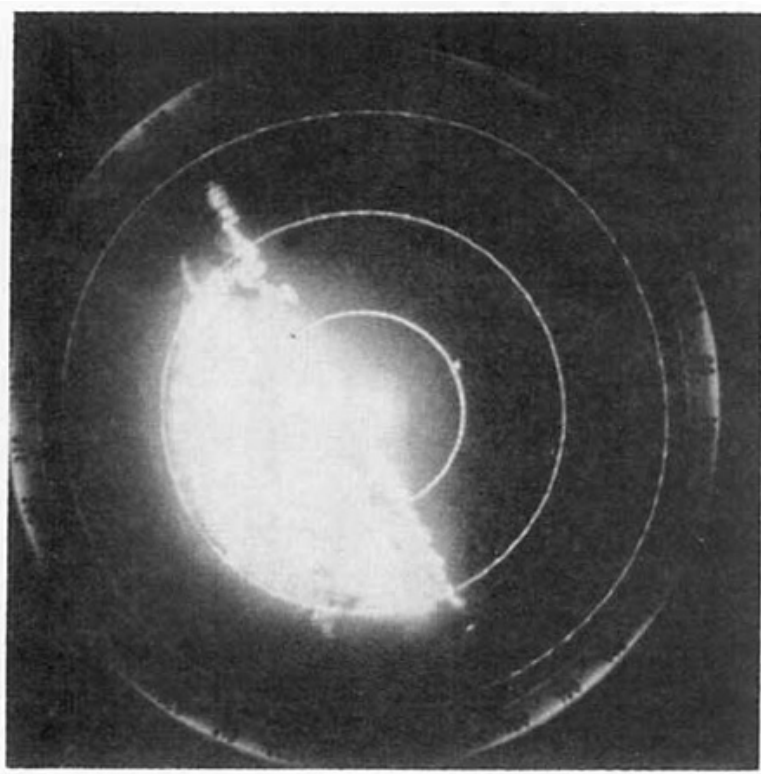

A. Continuous stratiform

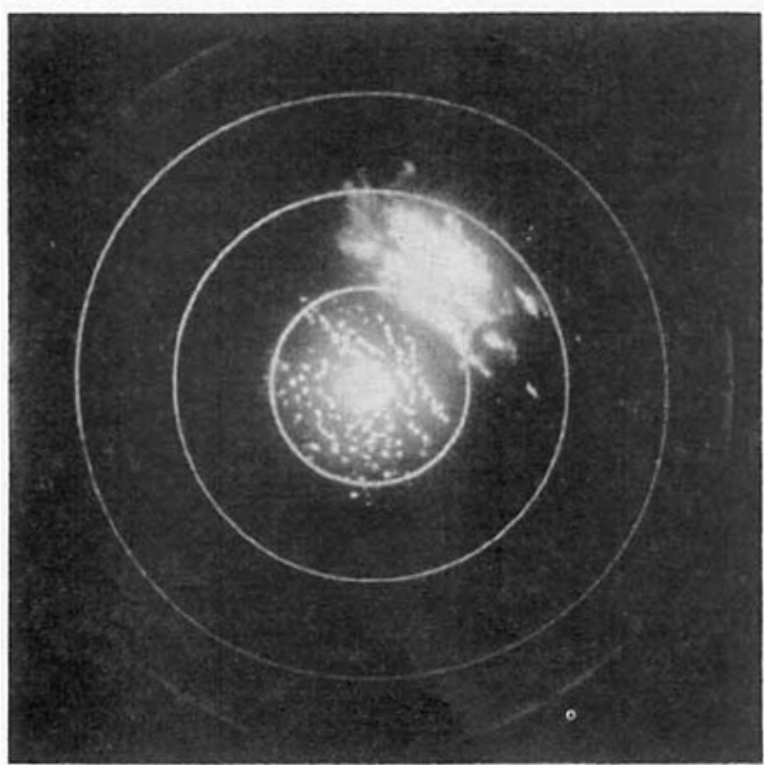

C. Small convective

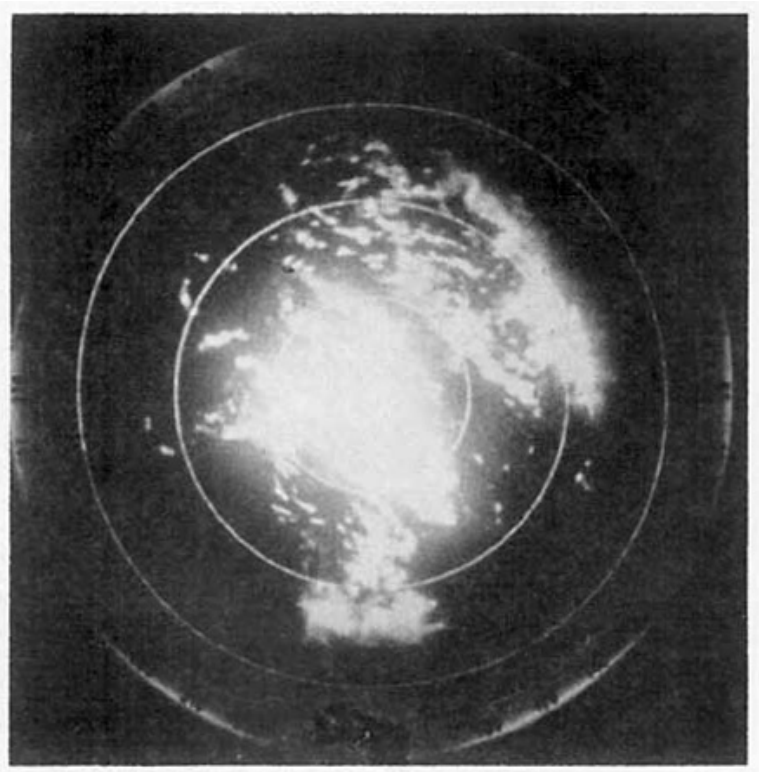

B. Ragged patches of stratiform

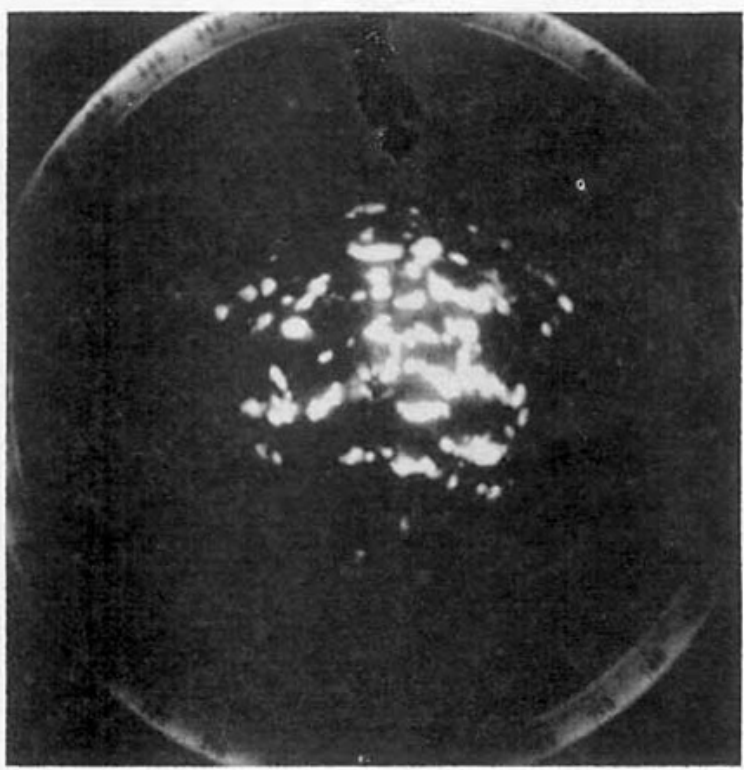

D. Large convective cells

FIG. 11. Typical maritime precipitation patterns, 150-mi range.

- , and H. Wexler, 1960: Cloud pictures from satellite TIROS I. Mon. Wea. Rev., 88, 79-87.

Nagle, R. E., 1960: Some preliminary results of radarscope photography conducted on weather reconnaissance flights over the Eastern Pacific Ocean. Proc. Eighth Weather Radar Conf., Boston, Amer. Meteor. Soc., 307-314.

Petterssen, S., 1956: Weather analysis and forecasting. New York, McGraw-Hill, 277-279.

Staff Members of the Department of Meteorology of the University of Chicago, 1947: On the general circulation of the atmosphere in middle latitudes. Bull. Amer. meteor. Soc., 28, 250-280.

Sternberg et al., 1960: Roundup on TIROS I. Astronautics, 5, p. 32.

Winston, J., 1960: Satellite pictures of a cut-off cyclone over the Eastern Pacific. Mon. Wea. Rev., 88, 295-314.

- , and L. Tourville, 1961: Cloud structures of an occluded cyclone over the Gulf of Alaska as viewed by TIROS I. Bull. Amer. meteor. Soc., 42, 151-165. 